\title{
Potensi biofisik ekosistem mangrove untuk ekowisata di kampung parambu, kabupaten jeneponto
}

\author{
Muhammad Arhan Rajab \\ Jurusan Manajemen Pariwisata, STIPAR Tamalatea, Makassar \\ Sekolah Ting gi Pariwis ata Tamalatea, Jl. Perintis Kemerdekaan Km. 12 Makassar \\ Kode Pos 90245, Telp. 0411 - 583330 \\ e-mail:arhanrajab@stipartamalatea.ac.id
}

\begin{abstract}
Abstrak
Penelitian ini dilaksanakan di Kampung Parambu, Kab. Jeneponto pada bulan Februari-Maret 2020. Penelitian ini bertujuan untuk (1) mengetahui potensi ekosistem mangrove di Kampung Parambu,Kab. Jeneponto; (2) mengetahui potensi tegakan ekosistem mangrove di Kampung Parambu,Kab.Jeneponto. Pendekatan yang digunakan adalah penelitian survey. Data y ang diperoleh dianalis is secara deskiptif dan kuantitatif. Hasil yang didapat potensi ekos is temmangrove di Kampung Parambu didominasioleh mangrove jenis Rhizophora sp. dengan total luas $10 \mathrm{Ha}$ (6 Ha baik, $3 \mathrm{Ha}$ rusak ringan dan $1 \mathrm{Ha}$ rusak berat) sementara potensitegakan mangrove rata-rata mencapai 20,000 pohon/ha dan volume 648.41 $\mathrm{m}^{3} / \mathrm{ha}$. Kondisiters ebut memberikan gambaran bahwa keberadaan sumberdaya ekosistemmangrovedi Kampung Parambu, Kab. Jeneponto cukup potensial untuk dimanfaatkan bagi mas yarakat lokal.Oleh karena itu kebijakan dalampengelolaan sumberday a ekosistemmangrove, perlu mempertimbangkan aspek biofisik untuk pengembangan lebih lanjut.
\end{abstract}

Kata Kunci: potensi, biofisik, ekowis ata, mangrove

\begin{abstract}
This research was conducted in Kampung Parambu, Kab. Jeneponto in February-March 2020.This study aims to (1) determine the potential of the mangrove ecosystem in Kampung Parambu, Kab. Jeneponto; (2) knowing the potential ofmangrove ecosystem stands in Kampung Parambu, Kab. Jeneponto. The approach used is survey research. The data obtained were analyzeddescriptivelyand quantitatively. The results obtained from the potential of mangrove ecosystemsinParambu Villageare dominated by mangrove species Rhizophora sp. with a total area of 10 Ha (6 Haisgood,3 Haisslightly damaged and 1 Ha is heavily damaged) while the potential ofmangrove stands is on average20,000 trees / ha and volume $648.41 \mathrm{m3} / \mathrm{ha}$. These conditions illustrate that the existence of mangrove ecosystem resources in Kampung Parambu, Kab. Jeneponto has enough potential tobeutilizedbythe local community. Therefore, policies in managing mangrove e cosystem resources need to consider biophysical aspects for further development.
\end{abstract}

Keywords: potential, biophysical, ecotourism, mangrove

\section{PENDAHULUAN}

Salah satu sumber daya alam yang dapat diperbaharui adalah ekosistem mangrove dengan berbagai biota yang memiliki nilai ekonomis yang tinggi. Hutan mangrove adalah vegetasi hutan yang tumbuh dan berkembang dengan baik disepanjang pantai, muara sungai yang dipengaruhi oleh pasang surut air laut. Hutan ini berada di titik pertemuan antara laut dan darat dengan ekosistem yang mempunyai bermacam-macam fungsi. Dari kurang lebih 15.9juta ha hutan mangrove didunia, sekitar $27 \%$ atau 4.25 juta ha diantaranya terdapat di Indonesia (Bengen, 2000).

Hutan Mangrove memiliki fungsi ekologis sebagai penyedia nutrien bagi biota perairan, tempat pemijahan dan asuhan bagi berbagai mac am biota, penahan abrasi, amukan angin taufan dan tsunami, penyerap limbah, pencegah intrusi air laut dan lain sebagainya. Hutan mangrove juga mempunyai fungsi ekonomis penting seperti penyedia kayu, daun-daunan sebagai bahan baku obat-obatan dan kegiatan ekowisata (Dahuri et al. 1996). 
Dalam pengembangan hutan mangrove sangat diperlukan untuk meningkatkan pendapatan ekonomi maupun kondisi sosial masyarakat sekitar, namun diperlukan pertimbangan, penilaian, dan analisis lingkungan (biofisik) yang baik bagi masyarakat tanpa harus memberikan dampak buruk bagi lingkungan dalam hal ini merusak ekosistem yang telah ada di dalam hutan mangrove. Karenanya keseimbangan lingkungan dan ekologi yang ada perlu menjadi perhatian dalam perencanaan pembangunan kaw asan hutan mangrove (Devitha, 2015).

Potensi ekosistem mangrove di Kabupaten Jeneponto tersebar pada tujuh wilayah kecamatan, yaitu Kecamatan Arungkeke, Kecamatan Batang, Kecamatan Tarowang, Kecamatan Tamalatea, Kecamatan Binamu, Kecamatan Bangkala, Kecamatan Bangkala Barat. Penyebaran kawasan sumberdaya ekosistem mangrove di Kabupaten Jeneponto secara keseluruhan yakni $282.50 \mathrm{Ha}$ (Kondisi baik 119.50 Ha, Rusak ringan 1.50 Ha dan Rusak berat $161.50 \mathrm{Ha})$.

Adanya penurunan luasan dan penyebaran kaw asan sumberdaya mangrove di Kabupaten Jeneponto dipengaruhi oleh beberapa faktor salah satunya yaitu alih fungsi lahan menjadi tambak. Selain itu secara umum persepsi masyarakat terhadap ekosistem mangrove belum menyeluruh bahkan cenderunf rendah. Padahal jika potensi ekosistem mangrove ini dikelola secara optimal (konsep ekowisata) dapat menjadi alternative penghasilan bagi masyarakat. Pengembangan ekowisata telah memberikan dampak positif berupa peningkatan pendapatan, pengeluaran dan asset produksi bagi masyarakat yang terlibat (Tafalas, 2010).

Dari 7 Kecamatan di Kabupaten Jeneponto ternyata beberapa wilayah masih dalam kondisi baik salah satunya mangrove di Kampung Parambu, Kecamatan Batang. Potensi mangrove ini sangat penting untuk dikelola secara optimal sehingga memberikan dampak yang kemudian dirasakan langsung oleh masyarakat.

Oleh karena itu dengan penelitian ini akan mengkaji potensi biofisik ekosistem mangrove untuk pengembangan ekow isata di Kampung Parambu, Kabupaten Jeneponto.

\section{METODE PENELITIAN}

Penelitian ini dilakukan di Kampung Parambu, Kab. Jeneponto, pada bulan Februari sampai Maret 2020. Lokasi ini dipilih dengan pertimbangan bahwa daerah tersebut merupakan salah satu kawasan ekosistem mangrove yang besar dan cukup baik untuk dikembangkan menjadi kawasan ekowisata.

Jenis penelitian yang digunakan adalah dengan menggunakan metode survey. Kegiatan survey penelitian dilakukan untuk mendata kondisi eksisting biofisik ekosistem mangrove di Kampung Parambu. Selain itu penelitian ini menggunakan kuesioner sebagai alat pengumpul data yang pokok dimana responden yang dijadikan sampel adalah masyarakat lokal di Kampung Parambu.

Populasi dalam penelitian ini adalah masyarakat Lokal Kampung Parambu, Kabupaten Jeneponto. Penentuan sampel dengan menggunakan rumus Slovin :

$$
\mathrm{n}=\frac{N}{1+n^{e}}
$$

Keterangan :

$\mathrm{n} \quad=$ Ukuran sampel

$\mathrm{N} \quad=$ Ukuran populasi

e $\quad=$ Persen kelonggaran ketidaktelitian karena kesalahan pengambilan sampel yang masih dapat ditolerir atau diinginkan dalam penelitian ini $(e=5 \%)$ 
Perhitungan ukuran sampel :

$$
\mathrm{n}=\frac{32}{1+\left(32 x\left(0.05^{2}\right)\right)}=29.63
$$

Jumlah sampel minimal yang digunakan dalam penelitian ini adalah 29.63 yang dibulatkan menjadi 30. sehingga jumlah sampel adalah 30 .

Teknik pengumpulan data yang digunakan dalam penelitian ini yaitu :

1. Observasi, yaitu pengamatan langsung terhadap kondisi biofisik ekosistem mangrove di lokasi penelitian yang terkait dengan tujuan penelitian.

2. Wawancara, yaitu mengumpulkan data dengan melakukan wawancara menggunakan kuisioner kepada pihak terkait yang berkaitan dengan penelitian.

Data yang dikumpulkan pada penelitian ini meliputi data primer dan data sekunder, dengan jenis data sebagai berikut :

1. Data primer, yaitu data yang diperoleh langsung dari lapangan melalui waw ancara dengan responden menggunakan kuisioner dan pengamatan (observasi) langsung di lapangan.

2. Data sekunder, yaitu data yang diperoleh dari instansi-instansi terkait dengan masalah dan obyek yang diteliti.

Data dianalisis secara deskriptif dan kuantitatif. Analisis data secara deskriptif digunakan untuk menjelaskan aktivitas masyarakat yang memanfaatkan ekosistem mangrove di Kampung Parambu. Analisis data secara kuantitatif digunakan untuk menghitung potensi tegakan mangrove.

\section{HASIL DAN PEMBAHASAN}

Kawasan sumberdaya ekosistem mangrove di Kampung Parambu, Kabupaten Jeneponto telah ada semenjak \pm 20 tahun yang lalu atau sekitar Tahun 1990-an. Ekosistem mangrove tersebar di sepanjang pantai Kampung Parambu. Data terakhir yang dirilis pasca rehabilitasi Tahun 2006 oleh Departemen Kelautan dan Perikanan Kabupaten Jeneponto Tahun 2010 menyebutkan bahw a saat ini luas kawasan ekosistem mangrove di Kampung Parambu memiliki luas \pm 10 Ha dengan rincian $6 \mathrm{Ha}$ dalam kondisi baik, 3 Ha dalam kondisi rusak ringan dan 1 Ha dalam kondisi rusak berat.

Berdasarkan hasil wawancara dan observasi langsung dengan masyarakat responden, kawasan ekosistem mangrove di Kampung Parambu memiliki kerapatan/ jarak tanam $1 \mathrm{~m}$ x 1 $m$ dan bila di lihat dari tingkatan umur mangrove dibagi menjadi tiga tingkatan. Untuk tingkatan I dan II terletak di sepanjang pantai sebelah timur merupakan kelompok mangrove yang memiliki usia $\leq 5$ tahun dan 5-15 tahun sedangkan untuk tingkatan III terletak di sepanjang pantai selatan merupakan kelompok mangrove yang memiliki usia 15-20 tahun.

Dengan melihat posisi Kampung Parambu secara geografis terletak pada kawasan pantai yang terbuka, sementara kondisi ekosistem mangrove yang diketahui sangat kuat untuk menahan terpaan ombak maka pada Tahun 2006 Dinas Kelautan dan Perikanan Kabupaten Jeneponto melakukan rehabilitasi dengan menanan bibit mangrove sebanyak 100,000 pohon.

Setelah melakukan observasi dilokasi penelitian Kampung Parambu mengenai kondisi tegakan ekosistem mangrove, maka diperoleh data kuantitatif tegakan mangrove jenis Rhizophora Sp. Seperti terlihat pada Tabel 1 sebagai berikut. 
Tabel 1. Potensi Tegakan Mangrove Jenis Rhizophora Sp. di Kampung Parambu, Batang, Kab. Jeneponto, Tahun 2020.

\begin{tabular}{|c|c|c|c|c|}
\hline \multirow[t]{2}{*}{ Tingkat Umur } & \multicolumn{2}{|c|}{ Rata-Rata } & \multirow{2}{*}{$\begin{array}{l}\text { Jumlah } \\
\text { Pohon }\end{array}$} & \multirow{2}{*}{$\begin{array}{c}\text { Volume } \\
\left(\mathbf{m}^{3}\right)\end{array}$} \\
\hline & $\begin{array}{l}\text { Tinggi } \\
\text { (m) }\end{array}$ & $\begin{array}{c}\text { Diameter } \\
\text { (m) }\end{array}$ & & \\
\hline TU I ( $\leq 5$ tahun $)$ & 4 & 0.03 & 25,000 & 70.65 \\
\hline TU II (5-15 tahun) & 6 & 0.08 & 20,000 & 602.88 \\
\hline TU III (15-20 tahun) & 7.5 & 0.12 & 15,000 & 1271.7 \\
\hline \multicolumn{3}{|c|}{ Rata-rata } & 20,000 & 648.41 \\
\hline
\end{tabular}

Sumber: Data Primer Kampung Parambu, 2020.

Keterangan :

1. TU I adalah tingkat umur mangrove golongan I yakni $\leq 5$ tahun.

2. TU II adalah tingkat umur mangrove golongan II yakni 5-15 tahun.

3. TU III adalah tingkat umur mangrove golongan III yakni 15-20 tahun.

Luas penyebaran kawasan sumberdaya ekosistem mangrove di Kampung Parambu mencapai $10 \mathrm{Ha}$, namun hanya ada $6 \mathrm{Ha}$ dalam kondisi baik (produktif) secara umum dibagi kedalam 3 tingkatan umur. Dengan perkiraan luas setiap tingkatan umur terhadap luas total yaitu TU I, TU II, dan TU III maka gambaran total kondisi tegakan ekosistem mangrove untuk setiap tingkatan umur sebagai total standing stok tegakan ekosistem mangrove di kampung Parambu.

Total standing stock tegakan ekosistem mangrove di Kampung Parambu seluas $6 \mathrm{Ha}$ untuk keseluruhan tingkatan umur mencapai 3,289.94 $\mathrm{m}^{3}$ dengan jumlah pohon sebanyak 125,000 batang.

Hasil analisis data kualitatif yang diperoleh dari tanggapan masyarakat responden yang bermukim dan beraktivitas di sekitar kawasan ekosistem mangrove mengenai beberapa aspek persepsi penilaian masyarakat terhadap kondisi tegakan sumberdaya ekosistem mangrove pada kurun waktu 5-10 tahun terakhir dapat dilihat pada Tabel 2.

Tabel2. Tanggapan Masy arakat Terhadap Kondisi Sumberdaya Ekosistem Mangrove di Kampung Parambu, Kabupaten Jeneponto, Tahun 2020.

\begin{tabular}{l|l|c}
\hline \multicolumn{1}{c|}{ Aspek Penilaian } & \multicolumn{1}{|c}{ Tanggapan Mas yarakat } & $\begin{array}{c}\text { Persentase } \\
(\mathbf{\%})\end{array}$ \\
\hline Luas Ekosistem Mangrove & $\sim$ Berkurang & 65 \\
& $\sim$ Tetap & 27 \\
& $\sim$ Bertambah & 8 \\
\hline Perkembangan Tegakan Mangrove & $\sim$ Lebih buruk & - \\
& $\sim$ Tetap & 69 \\
& $\sim$ Lebih Baik & 23 \\
\hline Penyebab Kerusakan EkosistemMangrove & $\sim$ Hama penyakit & 54 \\
& $\sim$ Konversi & 23 \\
& $\sim$ Ombak/angin & \\
\hline
\end{tabular}




\begin{tabular}{l|l|c}
\hline Dampak Kerusakan Ekosistem Mangrove & $\sim$ Abrasi & 62 \\
& $\sim$ Tergenang & 23 \\
& $\sim$ Pendapatan berkurang & 15 \\
& & \\
\hline RehabilitasiEkosistem Mangrove & $\sim$ Gagal & 46 \\
& $\sim$ Kurang berhasil & 35 \\
& $\sim$ Berhasil & 19 \\
\hline
\end{tabular}

Sumber : Data Primer Kampung Parambu, 2020.

\section{KESIMPULAN}

Potensi ekosistem mangrove di Kampung Parambu didominasi oleh mangrove jenis Rhizophora sp. dengan total luas $10 \mathrm{Ha}$ ( $6 \mathrm{Ha}$ baik, 3 Ha rusak ringan dan $1 \mathrm{Ha}$ rusak berat) sementara potensi tegakan mangrove rata-rata mencapai 20,000 pohon/ha dan volume 648.41 $\mathrm{m}^{3} / \mathrm{ha}$.

\section{Ucapan terima kasih}

Ucapan terima kasih kami ucapkan kepada seluruh masyarakat nelayan kecil Kampung Parambuyang menerima kami dengan baik untuk melakukan penelitian ini. Tak lupa juga kami haturkan ucapan terima kasih kepada Dinas Kelautan dan Perikanan Kabupaten Jeneponto dan Camat Batang atas bantuan untuk memberikan izin melakukan penelitian dan menyediakan data-data pendukung penelitian.

\section{DAFTAR PUSTAKA}

Bengen, D.G. 2000. Pedoman Teknis Pengenalan dan Pengelolaan Ekosistem Mangrove. Pusat Kajian Sumber Daya Pesisir dan Lautan. IPB. Bogor.

Dahuri R, Rais RJ, Ginting SP, Sitepu MJ. 1996. Pengelolaan Wilayah Pesisir dan Lautan Secara Terpadu. Jakarta (ID): Pradnya Paramita.

Tafalas. Muhiddin. 2010. Dampak Pengembangan Ekowisata Terhadap (Studi Kasus Ekowisata Kehidupan Sosial Dan Ekonomi Masyarakat Lokal Bahari Pulau Mansuar Kabupaten Raja Ampat). Sekolah Pascasarjana Institut Pertanian Bogor. Bogor

Windy. D. K. 2015. Potensi Ekonomi Ekosistem Hutan Mangrove Di Desa Kulu, Kecamatan Wori Kabupaten Minahasa Utara. Sekolah Pascasarjana Institut Pertanian Bogor. Bogor. 